\title{
Delayed gastric emptying: a novel gastrointestinal finding in Turner's syndrome
}

\author{
Annamaria Staiano, Mariacarolina Salerno, Salvatore Di Maio, Giuseppe Marsullo, \\ Antonio Marino, Daniela Concolino, Pietro Strisciuglio
}

\begin{abstract}
Aim-To evaluate gastric emptying in girls with Turner's syndrome to detect if gastrointestinal motor dysfunction was present.

Subjects-Thirteen girls (mean age 8.1 years) with Turner's syndrome, seven girls with familial short stature (6.1 years), and eight control girls (7.6 years).

Methods-Gastric emptying studies were performed by using $500 \mu \mathrm{Ci}$ of technetium $99 \mathrm{~m}$-sulphur colloid bound to a scrambled egg, and scintigraphic measurements were made for 60 to 90 minutes.

Results-Mean (SD) percentage retention of gastric isotope was significantly greater in girls with Turner's syndrome than in children with short stature and in controls. Furthermore, in contrast with control subjects, in whom there was an inverse linear relationship between gastric emptying rate and body mass index, in children with Turner's syndrome the delay in gastric emptying was independent of the body mass.

Conclusions-The results of the study suggest that delayed gastric emptying is detectable in girls with Turner's syndrome independent of age, body mass index, karyotype, and growth promoting treatment.
\end{abstract}

(Arch Dis Child 1996;75:440-443)

Keywords: Turner's syndrome, gastric emptying.

University Federico II, Naples, Department of Paediatrics

A Staiano

M Salerno

$S$ Di Maio

A Marino

Department of

Radiology

G Marsullo

\section{Department of}

Paediatrics, University

of Reggio Calabria,

Catanzaro, Italy

D Concolino

P Strisciuglio

Correspondence to:

Dr Annamaria Staiano,

Dipartimento di Pediatria,

Universita' Federico II, Via S

Pansini 5, 80131 Napoli,

Italy.

Accepted 16 July 1996

Typically, the clinical characteristics of Turner's syndrome include a combination of short stature, gonadal dysgenesis, and lymphoedema and other dysmorphic features. ${ }^{1}$ There are, however, no pathognomonic clinical features of this syndrome. Almost any combination of physical features can be seen with any $\mathrm{X}$ chromosomal abnormality, and severity of clinical features does not necessarily correlate with karyotypic findings. Genitourinary, skeletal, cardiovascular abnormalities, as well as skin, nail, and hair defects have been reported in girls with Turner's syndrome, randomly associated with the typical features. ${ }^{23}$ Moreover, Price showed a high incidence of chronic inflammatory bowel diseases in these patients. ${ }^{4}$

In 1980, Chen et al reported that in Turner's syndrome there was a high incidence of feeding difficulties in early childhood, including regurgitation and vomiting. ${ }^{5}$ More recently, it has been shown that infants with Turner's syndrome have significant feeding difficulties, oral-motor dysfunction, and possible pharyngeal and gastro-oesophageal disorders. ${ }^{\circ}$

The aim of our study was, therefore, to evaluate upper gastrointestinal motility in patients with Turner's syndrome in order to detect if gastrointestinal motor dysfunction was present in this disorder.

\section{Patients and methods}

The study population consisted of 13 girls with Turner's syndrome (mean age (SD) 8.1(4.1) years, range 3-14 years) and two comparison groups: seven girls with familial short stature (6.6 (4.2) years, range 3-14 years) and eight control girls (7.6(3.0) years, range 3-12 years). Further clinical characterisation of the two patient groups is described in table 1. Turner's syndrome was diagnosed on the basis of clinical features and confirmed in all patients by karyotype analysis. In eight patients $45 \mathrm{XO}$ karyotype was found, and five had mosaicism. None of the patients had breast development, while pubic hairs were present in five older patients with Tanner stage between II and III. ${ }^{7}$ Six patients were evaluated before the beginning of growth promoting treatment, two were treated with oxandrolone $(0.1 \mathrm{mg} / \mathrm{kg} /$ day $)$, three with subcutaneous growth hormone injections $(0.1 \mathrm{U} / \mathrm{kg} / \mathrm{day})$, and two with a combination of both treatment regimens.

Children with familial short stature were enrolled in the study to rule out the possibility of bias. None of the girls with familial short stature ( $<3$ rd centile) was affected by serious gastrointestinal disease and in all of them endocrinological or metabolic tests were normal.
GASTRIC EMPTYING STUDIES

Gastric emptying was measured as previously reported. ${ }^{8}$ In brief, a test meal consisting of one gastro-oesophageal reflux. None of these subjects was ultimately found to have any gastrointestinal disorder. All these girls had heights and weights between the 5 th and 95 th centiles.

All the subjects underwent gastric emptying studies, but only six of the girls with Turner's syndrome and the eight control children also underwent oesophageal manometry. Body mass index was used as a measure of obesity and was calculated by dividing the weight (in $\mathrm{kg}$ ) by the height $\left(\mathrm{m}^{2}\right)$.

In all cases, informed written consent for participation in this study was obtained from the parents. The investigation was approved by the ethical board of the University of Naples. 
scrambled egg, labelled with $500 \mathrm{Ci}$ of technetium-99m- sulphur colloid, in two slices of bread, with $100 \mathrm{ml}$ of water, was ingested after at least a four hour fast. Continuous scintigraphic measurements were then made with a gamma camera (General Electric), positioned over the abdomen of a supine subject. Time zero was defined as the time of meal completion. Data acquired with the gamma camera were stored on a small on-line computer for later analysis. After correction for decay of the technetium and patient movement, gastric emptying was quantitatively expressed as a percentage (CTt/CTo $\times 100$ ), where CTt is the count rate of technetium at any time in the stomach and CTo is the initial count rate of the technetium in the stomach.

\section{OESOPHAGEAL MANOMETRY}

Manometry was performed in fasting children without sedation, with the use of a triple lumen polyvinyl catheter, according to previously described methods. ${ }^{9}$ To assess peristaltic activity, only waves that were induced by wet swallows, preceded by 30 seconds of absent motor activity, were used. Contraction wave parameters (amplitude and duration) were only measured from the distal oesophagus and manometric measurements were taken from 10 wet swallows in each subject. Lower oesophageal sphincter pressure was measured as the mid-respiratory pressure with mean intragastric pressure as zero reference.

\section{STATISTICS}

Data are reported as mean (SD) throughout. Mean values across subjects groups were compared by using a one way analysis of variance. If the one way analysis of variance revealed significant differences, an unpaired, two tailed Student's $t$ test was applied for individual comparisons. In all cases a $p$ value of less than 0.05 was required for statistical significance. Statistical analysis was also performed with multiple regressions using partial and multiple correlation.

Table 1 Clinical features in the study population; values are mean (SD) or number

\begin{tabular}{llll}
\hline & $\begin{array}{l}\text { Turner's syndrome } \\
(n=13)\end{array}$ & $\begin{array}{l}\text { Familial short stature } \\
(n=7)\end{array}$ & $\begin{array}{l}\text { Controls } \\
(n=8)\end{array}$ \\
\hline Age (years) & $8.1(4.1)$ & $6.1(4.2)$ & $7.6(3.0)$ \\
Height (cm) & $112.7(21)$ & $102.0(22.6)$ & $123.4(21.0)$ \\
Body mass index & $18.5(2.4)$ & $16.5(1.2)$ & $15.5(3.4)$ \\
Obesity & 4 & 0 & 0 \\
Anorexia & 2 & 3 & 3 \\
Vomiting & 0 & 1 & 1 \\
Recurrent abdominal pain & 2 & 2 & 3 \\
Chronic constipation & 0 & 1 & 1 \\
\hline
\end{tabular}

*Obesity: weight $>20 \%$ over ideal body weight.

Table 2 Oesophageal manometry variables in children with Turner's syndrome and controls; values are mean (SD)

\begin{tabular}{lll}
\hline & $\begin{array}{l}\text { Controls } \\
(n=8)\end{array}$ & $\begin{array}{l}\text { Turner's syndrome } \\
(n=6)\end{array}$ \\
\hline LOS pressure (mm Hg) & $16.0(7.0)$ & $19.1(4.5)$ \\
LOS relaxation (\%) & $95.5(5.0)$ & $96.4(5.0)$ \\
Duration of oesophageal waves (sec) & $2.6(0.4)$ & $2.9(0.4)$ \\
Amplitude of oesophageal waves (mm Hg) & $59.8(18.7)$ & $56.8(23.2)$ \\
Abnormal motor response (\%) & $4.8(5.9)$ & $3.9(4.7)$ \\
\hline
\end{tabular}

LOS: lower oesophageal sphincter.

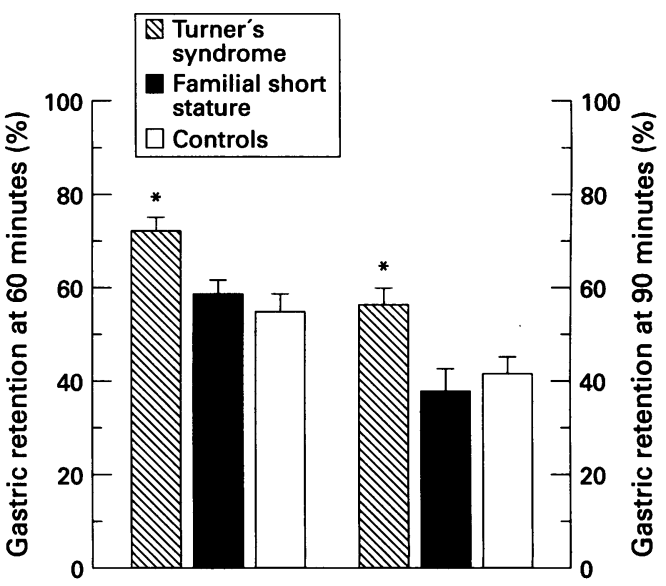

Figure 1 Mean (SEM) percentage of isotope retention in the stomach at 60 and 90 minutes. A significant increase in gastric retention at 60 and 90 minutes was noted for girls with Turner's syndrome when compared with the two other groups (one way analysis of variance for all groups, $p<0.01$. Asterisks indicate $p<0.01$ compared with each of the other two groups.

\section{Results}

As shown in fig 1, the percentage of retention of solids at 60 minutes was significantly greater $(\mathrm{p}<0.001)$ in patients with Turner's syndrome ( $72.0(9.9) \%$, range $57 \%-87 \%$ ) than in control subjects $(54.8(11.0) \%$, range $37 \%-64 \%)$ and in children with familial short stature (58.8 (7.8)\%, range $47 \%-68 \%$ ). Five of the 13 (38\%) girls with Turner's syndrome had a gastric emptying result at 60 minutes exceeding the mean and 2 SDs of the results in control children. The percentage of retention of solids at 90 minutes was also significantly $(p<0.01)$ higher in children with Turner's syndrome (56.3 (11.5)\%, range $36 \%-74 \%$ ) than in controls $(42.0(7.8) \%$, range $33 \%-53 \%)$ and in children with familial short stature ( 38.0 (12.8)\%, range $15 \%-54 \%)$. No differences were found in gastric emptying studies between children with familial short stature and controls (fig1).

Oesophageal manometry, shown in table 2, in the six children with Turner's syndrome did not show significant differences when compared with the mean value in our control population, previously reported. ${ }^{10}$

In control children linear regression analysis gave a correlation coefficient of $0.97(p<0.001)$ between retention of gastric isotope at $60 \mathrm{~min}-$ utes and the body mass index for the entire study group, whereas in girls with Turner's syndrome as well as those with familial short stature gastric retention was not correlated with body mass index ( $r=014, r=0.27$, respectively, fig 2). We did not find a correlation between gastric emptying rates and age, height, body surface area, or weight in any of the three study groups. Furthermore, in girls with Turner's syndrome gastric emptying delay was independent of karyotype and treatment with growth hormone or oxandrolone.

\section{Discussion}

The results of this study indicate that children with Turner's syndrome have gastric emptying delay compared with controls and those with familial short stature. The delay in gastric 


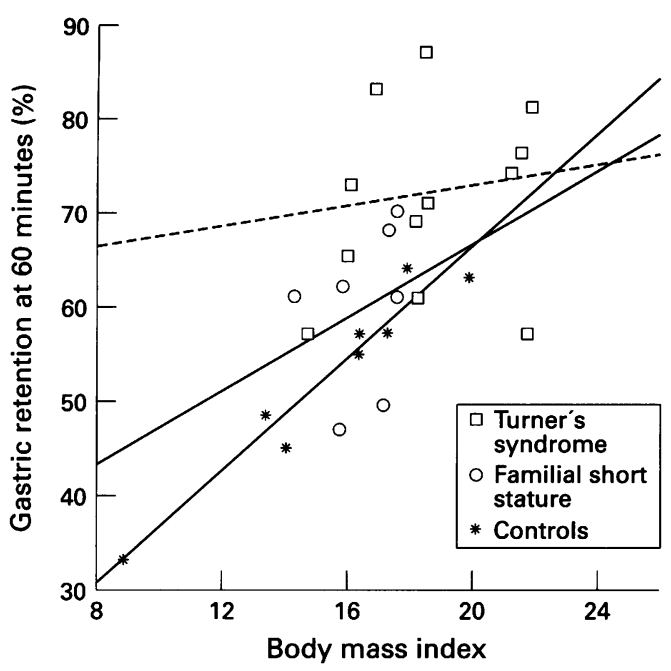

Figure 2 Body mass index related to percentage of isotope retention in the stomach at 60 minutes in girls with Turner's syndrome (dashed line), familial short stature, and controls.

emptying in children with Turner's syndrome is independent of age, weight, height, and body mass index, whereas in control children gastric emptying rate is inversely correlated with the body mass.

The association between poor weight gain and feeding difficulties in infants with Turner's syndrome has been previously reported. ${ }^{6}$ The poor weight gain of infants with Turner's syndrome has been related to early feeding problems and oral-motor dysfunction. However, the greatest difficulty was introducing solid food into their children's diet. The frequent reports by case group mothers of vomiting and regurgitation and the refusal to eat solid food suggested that some girls with Turner's syndrome could have a dysfunction of the lower gastro-oesophageal tract. In addition, the nasal regurgitation and the mildly nasal speech observed in affected adults could be indicative of pharyngo-oesophageal disorders. ${ }^{11}$

Our patients with Turner's syndrome and delayed gastric emptying had few upper gastrointestinal symptoms, even on detailed questioning. This finding is consistent with previous observations in different patients, such as in patients with congenital myopathies. $^{8}{ }^{12}$ It is probable that patients adapt slowly to the disturbance of gastrointestinal function, resulting in reduced perception of gastrointestinal symptoms. Furthermore, our patients with Turner's syndrome and delayed gastric emptying had normal motor function of the oesophagus, showing normal lower oesophageal sphincter pressure and relaxation with swallowing and normal amplitude and propagation of the peristaltic waves.

Based on the clinical features of Turner's syndrome, the obesity, the short stature, or gonadal failure could be potential causes of the delayed gastric emptying. Discordant data on gastric emptying are available in obese subjects; indeed, in some obese subjects abnormally rapid gastric emptying has been observed, but normal or even delayed gastric emptying has also been documented. ${ }^{13-15}$
The delayed gastric emptying in our patients with Turner's syndrome was independent of the body weight. In two patients with Turner's syndrome and normal weight, gastric emptying was markedly delayed, whereas the two most obese children with the syndrome had mildly delayed gastric emptying.

Regarding the short stature as implicated factor in gastric emptying delay, we did not find any correlation between height and gastric emptying rates: our patients with familial short stature had normal gastric emptying. Furthermore, previous study have found no differences in gastric emptying rates for liquid or solids in men compared with women or in premenopausal compared with postmenopausal women. ${ }^{13}$ These findings suggest that gonadal failure in Turner's syndrome, a typical early feature in affected infants and young children, is not implicated in the delay of gastric emptying.

Our study indicates an inverse linear correlation between gastric emptying and body mass in control subjects, whereas in children with Turner's syndrome, as well as in children with familial short stature, gastric emptying rates are independent from the body mass. Rates of gastric emptying of solid food differ considerably among control children, depending on their varying body mass; heavier normal children empty their gastric content more slowly and this finding is according with results in adult subjects. ${ }^{16}$ How the gastric events that empty solid food are related to the eventual body mass must be considered in control subjects; nevertheless, in those with Turner's syndrome, the delay in gastric emptying is independent of the body mass.

In contrast from the somatic stigmata attributable to lymphatic hypoplasia causing lymph fluid stasis resulting in distention of the main contributory lymphatic ducts and in generalised lymphoedema, ${ }^{17}$ we don't know the reasons responsible for the delay of gastric emptying in our children. However, our study demonstrates clearly that girls with Turner's syndrome present delay of gastric emptying rates for solid food which, in contrast with controls, is independent from the body mass. Finally, regardless of the specific mechanisms responsible for the findings, we believe that impaired gastric motility could represent a novel gastrointestinal finding of this syndrome.

1 Hall JG, Gilchrist DM. Turner syndrome and its variants. Pediatr Clin North Am 1990;37:1421-40.

2 Brook CGD. Turner syndrome. Arch Dis Child 1986;61: 305-9.

3 Palmer CG, Reichmam A. Chromosomal and clinical findings in 110 females with Turner syndrome. Hum Genet 1976;35:35-49.

4 Price WH. A high incidence of chronic inflammatory bowel disease in patients with Turner's syndrome. $\mathcal{F}$ Med Genet 1979;16:263-6.

5 Chen H, Faigessbaum D, Weiss H. Psychosocial aspects of patients with the Ulrich-Turner syndrome. Am $\mathcal{F}$ Med Genet 1981;8:191-203.

6 Mathisen B, Reilly S, Skuse D. Oral-motor dysfunction and feeding disorders of infants with Turner syndrome. Dev Med Child Neurol 1992;34:141-9.

7 Marshall WA, Tanner JM. Variations in patterns of pubertal changes in girls. Arch Dis Child 1969;44:291-303.

8 Staiano A, Del Giudice E, Romano A, et al. Upper gastrointestinal tract motility in children with progressive muscular testinal tract motility in children with
dystrophy. $\mathcal{f}$ Pediatr 1992;121:720-4.

9 Staiano A, Corazziari E, Andreotti MR, Clouse RE.

Staiano A, Corazziari E, Andreotti MR, Clouse RE.
Esophageal motility in children with Hirschsprung's disease. Am $\mathcal{F}$ Dis Child 1991;145:310-3. 
10 Staiano A, Cucchiara S, Del Giudice E, Andreotti MR, Minella R. Disorders of esophageal motility in children with psychomotor retardation and gastroesophageal reflux. Eur f Pediatr 1991;150:638-41.

11 Hall JG. The management of the adult with Turner syndrome. The natural history of Turner syndrome. In Rosenfed RG, Grumbach MM, eds. Turner syndrome. New York: Marcel Dekker, 1990:495-504.

12 Horowitz M, Maddox A, Maddern GJ, Wishart J, Collins PJ, Shearman DJC. Gastric and esophageal emptying in dystrophia myotonica. Gastroenterology 1987;92:570-7.

13 Wright RA, Krinsky S, Fleeman C, Trujillo J, Teague E. GasWright RA, Krinsky S, Fleeman C, Trujillo J, Teague E. Gas-
tric emptying and obesity. Gastroenterology 1978;74:1258-60.
14 Horowitz M, Collins PJ, Cook DJ, Harding PE, Shearman DJC. Abnormalities of gastric emptying in obese patients. Int $\mathcal{F}$ Obes 1983;7:415-21.

15 Sasaki H, Nagulesparan M, Dubois A, et al. Gastric function and obesity: gastric emptying, gastric acid secretion and plasma pepsinogen. Int $\mathcal{f}$ Obes $1984 ; 8: 183-90$.

16 Lavigne ME, Wiley ZD, Meyer JH, Martin P, MacGregor II. Gastric emptying rates of solid food in relation to body size. Gastroenterology 1978;74:1258-60.

17 Oyata T, Matsuo N. Turner syndrome and female sex chromosome aberrations: deduction of the principal factors involved in the development of clinical features. Hum Genet 1995;95:607-29.

\section{Physiology of fat}

A fascinating new area of physiology is unfolding before our eyes after the identification of the $o b$ gene in 1994. The gene product is a protein, leptin, which is a hormone secreted by adipocytes. In $o b / o b$ mice no leptin is produced. They become very obese but with exogenous leptin they eat less, their metabolic rate increases, and they lose weight.

Now researchers in the USA (Robert V Considine and colleagues, New England fournal of Medicine 1996; 334: 292-5) have shown that obese people have high serum levels of leptin (mean $31.3 \mathrm{ng} / \mathrm{ml} v 7.5 \mathrm{ng} / \mathrm{ml}$ in non-obese) which fall when they lose weight, and serum leptin correlates well with body fat as per cent of body weight measured by bioelectrical impedance. The adipocyte content of $o b$ mRNA was also increased in the obese subjects.

Obese rodents respond better to intraventricular leptin than to peripheral administration and from this and other evidence it is suggested that a hypothalmic mechanism is involved. This could involve the hypothalamic appetite-stimulating neuropeptide, neuropeptide $\mathrm{Y}$, or appetite decreasing neuropeptides. Both insulin and glucocorticoids stimulate leptin production.

It seems therefore that there is a classical feedback loop and that in obesity there is impaired central sensitivity to leptin possibly implying leptin receptor abnormality in the hypothalamus. Genetically normal rodents which become obese through forced feeding also become leptin insensitive indicating that, in some, leptin insensitivity could be secondary. This extremely interesting (and potentially highly lucrative) story continues to unfold. Presumably as well as simple obesity, this new knowledge could possibly throw more light on childhood obesity syndromes such as the Prader-Willi syndrome.

ARCHIVIST 